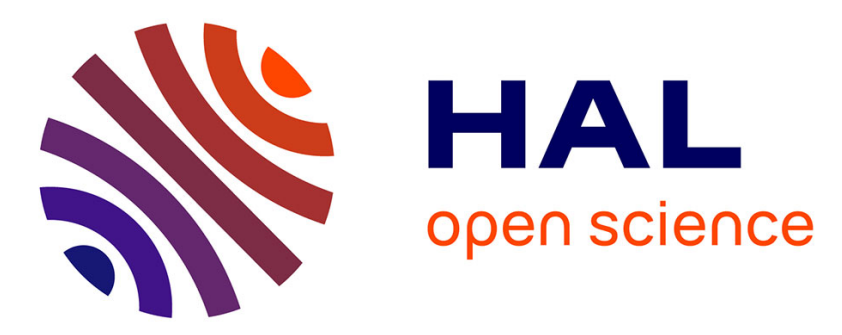

\title{
An analytical model taking feed rate effect into consideration for scallop height calculation in milling with torus-end cutter
}

Stéphane Segonds, Philippe Seitier, Cyril Bordreuil, Florian Bugarin, Walter Rubio, Jean-Max Redonnet

\section{To cite this version:}

Stéphane Segonds, Philippe Seitier, Cyril Bordreuil, Florian Bugarin, Walter Rubio, et al.. An analytical model taking feed rate effect into consideration for scallop height calculation in milling with torusend cutter. Journal of Intelligent Manufacturing, 2017, 10.1007/s10845-017-1360-0 . hal-01826032

\section{HAL Id: hal-01826032 \\ https://hal.science/hal-01826032}

Submitted on 23 Oct 2019

HAL is a multi-disciplinary open access archive for the deposit and dissemination of scientific research documents, whether they are published or not. The documents may come from teaching and research institutions in France or abroad, or from public or private research centers.
L'archive ouverte pluridisciplinaire HAL, est destinée au dépôt et à la diffusion de documents scientifiques de niveau recherche, publiés ou non, émanant des établissements d'enseignement et de recherche français ou étrangers, des laboratoires publics ou privés. 


\title{
An analytical model taking feed rate effect into consideration for scallop height calculation in milling with torus-end cutter
}

\author{
Stéphane Segonds $^{1}$ - Philippe Seitier $^{1}$ - Cyril Bordreuil $^{2}$ - Florian Bugarin $^{1}$ - Walter Rubio ${ }^{1}$ - Jean-Max \\ Redonnet $^{1}$
}

\begin{abstract}
Feed rate effect on scallop height in complex surface milling by torus-end mill is rarely studied. In a previous paper, an analytical predictive model of scallop height based on transverse step over distance has been established. However, this model doesn't take feed rate effect into consideration. In the present work an analytical expression of scallop height, including feed rate effect, is detailed in order to quantify feed rate effect and thus to estimate more precisely the surface quality. Then, an experimental validation is conducted, comparing the presented model predictions with experimental results. Actually, the share of the scallop height due to feed effect is highly dependent on the machining configuration. However, most of time, the feed effect on total scallop height values is far from being negligible.
\end{abstract}

Keywords Free-form surface $\cdot \mathrm{CNC}$ machine-tool . End-mill $\cdot$ Toroidal cutter $\cdot$ Effective tool radius $\cdot$ Feed rate . Scallop height

\section{Introduction}

\section{Context}

The end machining of complex parts is widely used in the field of molds and dies for which the machining time is

Stéphane Segonds

stephane.segonds@univ-tlse3.fr

1 Université Fédérale de Toulouse Midi-Pyrénées, Institut Clément Ader - CNRS UMR 5312 - UPS/INSA/Mines Albi/ISAE, 3, rue Caroline Aigle, 31400 Toulouse, France

2 Laboratoire de Mécanique et de Génie Civil, Université de Montpellier - CC048, 163 rue Auguste Broussonnet, 34090 Montpellier, France long and therefore expensive. From a geometrical point of view, the precise control of the machine is essential to ensure that the path followed by the tool corresponds to the awaited geometry of the workpiece, this aspect has been widely studied [see Lasemi et al. (2010) for a review of free-form surface CNC machining state of art].

The choice of machining strategy then sets the succession of tool paths, their characteristics and their relative positioning to meet the specifications in terms of shape and surface roughness imposed by the design office-Chețan et al. (2014). Accurate knowledge of the geometrical characteristics of the traces due to the tool displacement on the surface is essential. For this, many studies on tool path planning have focused on the calculation of the spacing between the successive toolpaths in order to ensure that local scallop height on the machined surface remains lower than the maximum allowed value - Cheţn et al. (2014) and Senatore et al. (2012).

For a given tool geometry, often imposed by the shape and the accessibility of the workpiece, two levers exist to limit the overall machining time: adapt the path so as to limit the path length of the tool and speed up the movement of the tool.

Studies on the first lever, that is to limit the length of the tool path, are numerous, the trajectories are calculated so that the scallop height between two consecutive paths is higher as possible without exceeding the imposed maximum heightDjebali et al. (2015), Perles et al. (2015) and Redonnet et al. (2016). The problem is generally to space the more the paths to minimize tool-path length and thereby the machining time.

However, the effects of the second lever, that is to speed up tool movement by increasing the feed rate, are rarely studied since a hypothesis commonly accepted is to assimilate the trace left by the tool to a smooth groove, neglecting the traces generated by the passages of successive cutter teeth, as in 
Redonnet et al. (2013). This correct assumption in the case of machining by grinding tool like (Denkena et al. 2010, 2013), seems also to be correct in the case of milling at low feed rate. The notion of "low feed rate" remains largely subjective and in most cases it should be possible to use higher feed rate than it is for finishing operation due to the low depth of cut and thus low cutting forces-Tai and Fuh (1994). It can be noted that (Kim and Chu 1999) propose a method to take into account the effect of the feed rate but it is however difficult to apply in the case of machining a complex surface with torus-end mill. The aim of the present paper is to set an easy to use analytic model to calculate feed rate effect on total scallop height.

In the context of freeform surfaces machining, the choice of the shape of the tool is of prime importance for the machining of free-form surfaces. Indeed, the trace left by the tool in the material not only depends on the movement of the tool, but also on the shape of the tool itself. The tool still often chosen for this type of machining is the ball-end one because the flat-end tool leaves sharp and unsightly marks on the surface-Kim and Chu (1994); Cho et al. (1993). However, more and more studies [like Bedi et al. (1997) or Redonnet et al. (2000) among others] point that the toroidal tool, when correctly used, generates a lower scallop height than the ballend tool (all other parameters being equal). Moreover, this type of tool is increasingly used in CNC machining studies [see Duan et al. (2015), Du et al. (2012) or He and Chen (2016) among others]. The toroidal tool thus appears as the best choice for machining free-form surfaces, so it is the one that will be chosen for the present study. Besides, ball-end mill and flat-end mill are only particular cases of toric-end mill (considering respectively tip radius equal to mill radius and tip radius equal to zero). The proposed following model can thus be applied to these particular cases.

\section{Articles contribution}

The present study concerns the definition of an analytical model of the scallop height including the effect of the feed rate. The main objective of this work is to set up an easy to use analytical expression that can be quickly calculated.

The article is organized as follows: first, the analytical study developed in Redonnet et al. (2013) is extended to take into account the effects of feed rate. This previous work provides an analytical model for calculating the effective radius which allows the determination of the scallop height in case of low feed rate. However this model does not provide the analytical calculation of the peak height resulting from successive marks left by tool teeth, which may be significant for high feed rates as stated in the conclusion of the present paper.
Second, a method for taking into account the actual geometry of the cutter, with possible runouts between mill teeth is detailed.

In the next part theoretical results provided by these analytical models are then compared to experimental results coming from measurements performed on a test piece in order to validate the proposed model.

The fourth part is devoted to the analysis of the results and how they may be exploited to improve real machining process. Then, takes place a discussion where pros and cons of our method are commented as well as few key points concerning assumptions made to reach the result.

As a conclusion, a summary of the advances provided by this work is proposed before some perspectives are presented.

\section{Analytical model of scallop height}

\section{Context and analytic expression}

A key parameter in the generation of machined scallops is the effective radius of the tool denoted $R_{\text {eff }}$, which can be defined as the projection in a plane normal to feed direction, of the trace left by the tool into the material. The effective cutter radius and sweep curve notions are largely used in works addressing constant scallop height machining planning. Initially introduced in Suresh and Yang (1994) and Lin and Koren (1996) using a ball-end cutter, they have been adapted in Lee (1998) and Can and Ünüvar (2010) for a flat-end mill, and in Chen and Song (2006) and Pi et al. (1998) for the torus milling cutter, tools for which the effective radius assumes its full significance.

Indeed, the effective radius of the tool is characteristic of scallop height $s_{h}$. Denoting $d$ the distance defining the next parallel plane position, the step over distance $s_{o d}$ can be readily determined as it is directly related to $d$ by the angle characterizing the local inclination of the surface in a plane normal to the machining direction (see Figs. 1,2).

Demonstrating that the step over distance is directly related to the cutter effective radius is thus equivalent to demonstrating that distance $d$ depends directly on that effective radius. This has been proven in Redonnet et al. (2013), which also give the analytical relation between $d, R_{e f f}$ and $s_{h}$. In this previous study a first approach to calculate analytically the effective radius of a torus milling cutter moving in pure translation was presented. This approach was based on the two following lemmas:

Lemma 1 Let $\mathcal{P}$ be the mathematical operation for projection along the feed direction $\mathbf{F}$ in a plane normal to $\mathbf{F}$. Let $\mathbf{T}_{\mathbf{p}}(v)$, be the curve resulting from the projection along $\mathcal{P}$ of the cutter envelope. Let $\mathbf{E}(t)$ be the ellipse resulting from the projection along $\mathcal{P}$ of the cutter centre-torus circle, and 
$\mathbf{o E}(t)$ an offset exterior to that ellipse with a value equal to the radius of the cutter torus. Then the two curves $\mathbf{T}_{\mathbf{p}}(v)$ and $\mathbf{o E}(t)$ are coincident.

Lemma 2 The radius of curvature of a plane offset curve is equal to the radius of curvature of the original curve augmented by the offset value.

Once demonstrated these lemmas, the effective radius of the toroidal cutter can be calculated considering the projection of the torus center circle in a plane normal to the machining direction and the $r$-offset of the resulting ellipse. The validity of this approach is fully demonstrated in Redonnet et al. (2013). It is also stated that this demonstration is only valid for pure translation movement of the cutter. This implies that hereafter presented study is valid for any 3 -axis machining strategy.

For torus-end mill, the tool-center surface is defined by:

$\mathbf{S}_{\mathbf{o}}(u, v)=\mathbf{S}(u, v)+r \mathbf{n}(u, v)+(R-r) \mathbf{n}_{\mathbf{p}}(u, v)$

where:

- $\mathbf{S}(u, v)$ is the surface to be machined

- $\mathbf{n}(u, v)$ is the vector normal to $\mathbf{S}(u, v)$ at the $(u, v)$ point

$-R$ is the outer toric end mill radius

$-r$ is the torus radius

and $\mathbf{n}_{\mathbf{p}}(u, v)$ is calculated using the vector $\mathbf{Z}$ representing the $\mathrm{Z}$-axis of the machine by:

$\mathbf{n}_{\mathbf{p}}(u, v)=\mathbf{Z} \times \frac{\mathbf{n}(u, v) \times \mathbf{Z}}{\|\mathbf{n}(u, v) \times \mathbf{Z}\|}$

Please note that, for simplicity reasons, all the following figures are drawn presenting the machining of a plane surface. However the present study provides the complete formulas allowing to evaluate the effective scallop height taking into account feed rate effect and local curvatures of the surface. The only hypothesis made on the free form surface is that local curvatures are considered constant. Thus the depicted content is valid for any free form surfaces.

Let the machining direction being called $\mathbf{F}_{\mathbf{p}}$ that is considered in the $(X, Y)$ plane of machine axes, i.e. the direction of $\mathbf{F}_{\mathbf{p}}$ corresponds to the projection of the feed rate vector $\mathbf{F}$, in the plane $(X, Y)$-see Fig. 1.

As demonstrated in Redonnet et al. (2013) the analytical expression of the effective radius of a torus-end mill moving in translation is:

$R_{e f f}=\frac{(R-r) \cos ^{2}(\alpha)}{\sin (S)\left(1-\sin ^{2}(\alpha) \sin ^{2}(S)\right)}+r$

where

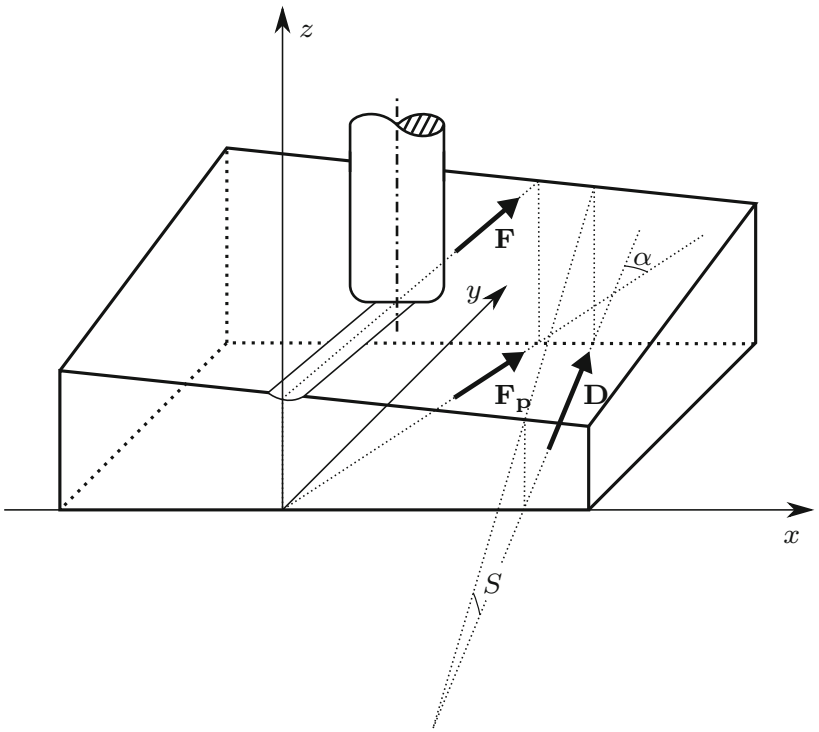

Fig. 1 Geometrical description of the parameters
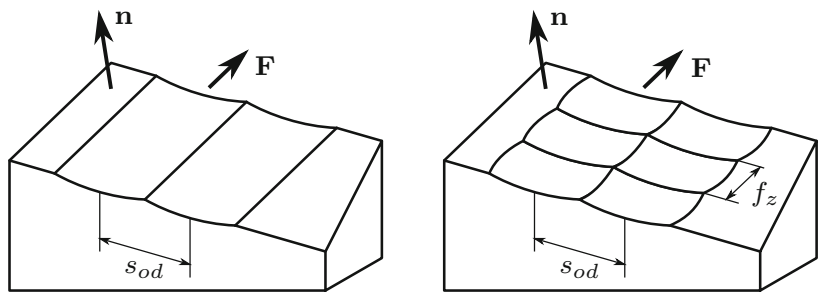

Fig. 2 Illustrating the secondary scallop peak

- $S$ is the steepest slope of the workpiece surface at the tool/workpiece contact point (Fig. 1)

- and $\alpha$ is the angle between the direction of steepest slope projected in the plane $(X, Y)$ (denoted $\mathbf{D}$ in Fig. 1) and the vector $\mathbf{F}_{\mathbf{p}}$

Additionally, the feed rate value is denoted $F$ (Fig. 2). In other words $F=\|\mathbf{F}\|$.

According to Redonnet et al. (2013), this formula is only valid at the cutter-contact point, but allows to estimate quite precisely the scallop height. Using this formula, the calculation of step over distance $s_{o d}$ at a point can be done instantly compared to the numerical methods previously used that required an important computation time, as it has been detailed in Redonnet et al. (2013). However, the effect of feed rate and the wave height that will appear due to distance between mill teeth passages at high feed rate may not be taken into account by using the only previous formula to determine the step over distance, and thus, effective maximum scallop height may be underestimated. Indeed, the more feed rate increase and the more wave height due to the mill teeth distance increase (Fig. 2). 
The work of Redonnet et al. (2013) has established the analytical expression of the effective radius of the imprint left by a torus-end mill machining with a feed rate vector $\mathbf{F}$. The effective radius is the radius of curvature of the trace measured in a plane perpendicular to the tool displacement. To take into account the fact that the tool is composed of teeth whose successive passages leave traces which one wishes to calculate the height, it is necessary to evaluate the effective radius of the secondary track that is named transverse effective radius and denoted $T R_{\text {eff }}$ (see Fig. 3). The procedure for determining the expression of $T R_{e f f}$ is globally the same than the one used to obtain the expression of $R_{\text {eff }}$ in Redonnet et al. (2013). Therefore complete calculations are not detailed in the present paper but main steps of the mathematical demonstration are stated hereafter. Initially, the equation of the ellipse given by the projection of the cutter torus center into a plane normal to the cutting speed vector is considered. In its own reference frame the equation of this ellipse is:

$\mathbf{E}(t)=\left(\begin{array}{c}(R-r) \cos (t) \\ (R-r) \frac{\tan (S) \cos (\alpha)}{\sqrt{1+\tan ^{2}(S) \cos ^{2}(\alpha)}} \sin (t) \\ 0\end{array}\right) t \in[0,2 \pi]$

Then $\rho_{E}$, the radius of curvature of this ellipse at the cutter contact point corresponding to a cutting speed vector perpendicular to feed direction, is calculated:

$\rho_{E}=\frac{(R-r)}{\sin (\psi)}\left(1+\cos ^{2}(t)\left(\sin (\psi)^{2}-1\right)\right)^{3 / 2}$

where $\psi$ is the angle between the vector $\mathbf{F}$ and its projection on the plane $(X, Y)$

Using Lemma 1 previously stated, this expression can be reduced to:

$\rho_{E}=\frac{(R-r) \cos ^{2}(\alpha)}{\sin (S)\left(1-\sin ^{2}(\alpha) \sin ^{2}(S)\right)}$

Thus, using Lemma 2, it is easy to achieve the expression of the secondary effective radius done by the circular tip of the torus-end cutter:

$T R_{e f f}=\frac{(R-r) \cos ^{2}\left(\alpha+\frac{\pi}{2}\right)}{\sin (S)\left(1-\left(\sin ^{2}\left(\alpha+\frac{\pi}{2}\right) \sin ^{2}(S)\right)\right)}+r$

In other words the expression of the transverse effective radius ( $T R_{\text {eff }}$ ) characterizing the geometry of the imprint left by the cutting tool animated by a movement whose com-

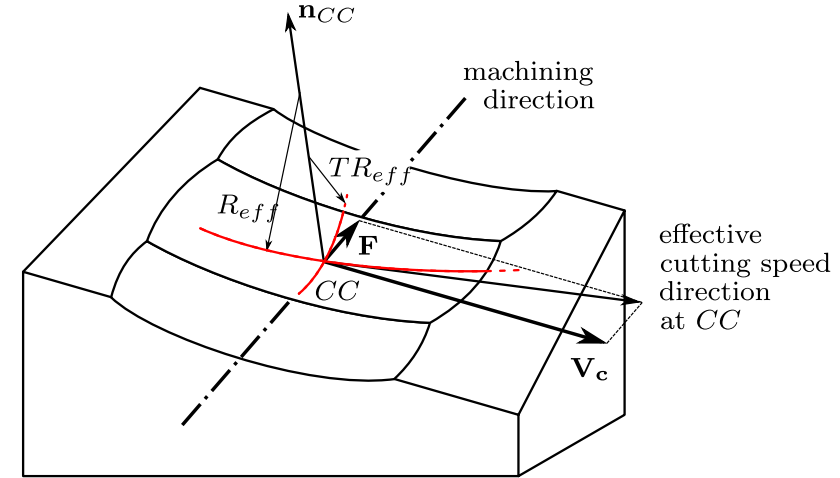

Fig. 3 Illustrating the parameters $R_{\text {eff }}$ and $T R_{\text {eff }}$

ponents are $\mathbf{F}$ and $\mathbf{V}_{\mathbf{c}}$ (see Fig. 3 below) is given by:

$T R_{e f f}=\frac{(R-r) \sin ^{2}(\alpha)}{\sin (S)\left(1-\cos ^{2}(\alpha) \sin ^{2}(S)\right)}+r$

\section{Analysis of the expression of transverse effective radius}

In relation (3), angle $\alpha$, characterizing the machining direction projected in the plane $(X, Y)$, is only taken into consideration through expressions of $\cos ^{2}(\alpha)$ and $\sin ^{2}(\alpha)$. It can thus be asserted that all other parameters being equal, the value of the transverse effective radius is the same for values $\alpha$ and $\alpha+\pi$. This is equivalent to say that for a given point, the values of the transverse effective radius are the same whether up milling or down milling in a diametrically opposite direction. This result is unsurprising in so far as the study of the transverse effective radius is based on a projection in a plane normal to the machining direction.

Moreover, analysis of relation (8) shows that for $\alpha=0$, $T R_{e f f}=r$, which constitutes the minimum value of the effective radius for a torus milling cutter. For slope angle of $S= \pm \frac{\pi}{2}$ and a machining direction angle of $\alpha= \pm \frac{\pi}{2}$, meaning that a wall is machined in rolling, the $T R_{\text {eff }}$ value is equal to $R$.

Using the values of $R_{e f f}$ and $T R_{e f f}$, it is possible to assess the scallop height $s_{h}$ for a given machining strategy. This height will depend on the value of the step over distance $s_{o d}$ and the feed per tooth $f_{z}$.

To date, the scallop height is calculated taking into account only the effective radius in the configuration presented on Fig. 5, it is treated as the distance $h_{1}$ and is calculated in a plane perpendicular to the feed rate direction along the normal to the nominal profile.

Let $\varrho$ be the local radius of curvature of the surface in this plane, $h_{1}$ may be calculated using the Al-Kashi formula in the triangle $\mathbf{C H O}$ (see Fig. 4 where $\mathbf{O}$ is the center of curvature): 


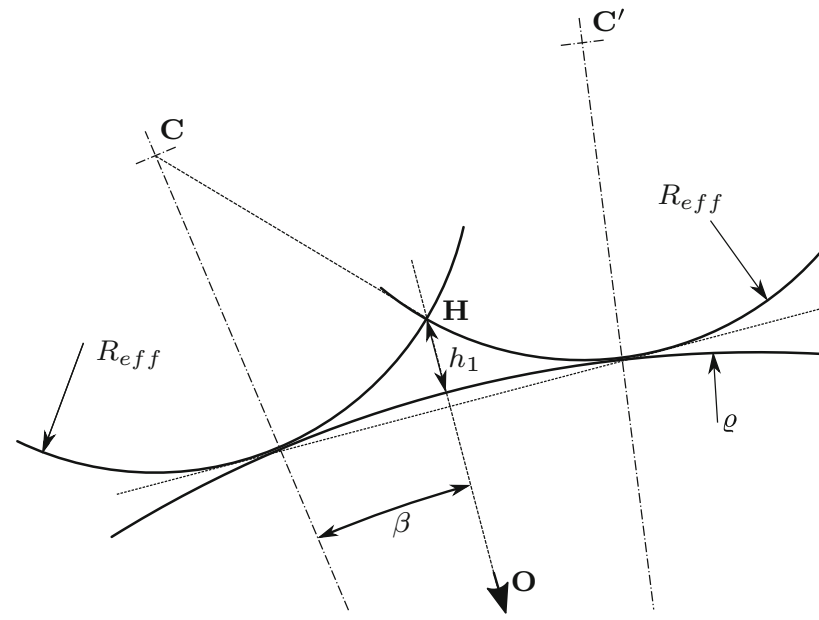

Fig. 4 Scallop height calculation taking into account the local curvatures of the surface

$R_{e f f}^{2}=\left(\varrho+h_{1}\right)^{2}+\left(\varrho+R_{e f f}\right)^{2}-2 \cos (\beta)\left(\varrho+R_{e f f}\right)\left(\varrho+h_{1}\right)$

Solving this 2 nd order equation gives:

$$
\begin{aligned}
h_{1}^{\prime}= & \varrho(1-\cos (\beta))+R_{e f f}^{2} \cos (\beta) \\
& +\sqrt{R_{e f f}^{2}-\sin ^{2}(\beta)\left(\varrho+R_{e f f}\right)^{2}}
\end{aligned}
$$

or

$$
\begin{aligned}
h_{1}^{\prime \prime}= & \varrho(1-\cos (\beta))+R_{e f f}^{2} \cos (\beta) \\
& -\sqrt{R_{e f f}^{2}-\sin ^{2}(\beta)\left(\varrho+R_{e f f}\right)^{2}}
\end{aligned}
$$

The right value is obviously $h_{1}^{\prime}$ which is the smaller one. The second one, $h_{1}^{\prime \prime}$, corresponds to the second intersection point between the two $R_{\text {eff }}$ radius circles.

Thus, the $h_{1}$ value is given by:

$$
\begin{aligned}
h_{1}= & \varrho(1-\cos (\beta))+R_{e f f}^{2} \cos (\beta) \\
& -\sqrt{R_{e f f}^{2}-\sin ^{2}(\beta)\left(\varrho+R_{e f f}\right)^{2}}
\end{aligned}
$$

When the surface can be considered as locally plane, the Eq. (12) can be approximated as (13) here after (see Fig. 5):

$h_{1}=R_{e f f}-\sqrt{R_{e f f}^{2}-\frac{s_{o d}^{2}}{4}}$

This approximation is discussed in "Discussion" section and the relation between these two expressions of $h_{1}$ is detailed in "Appendix".
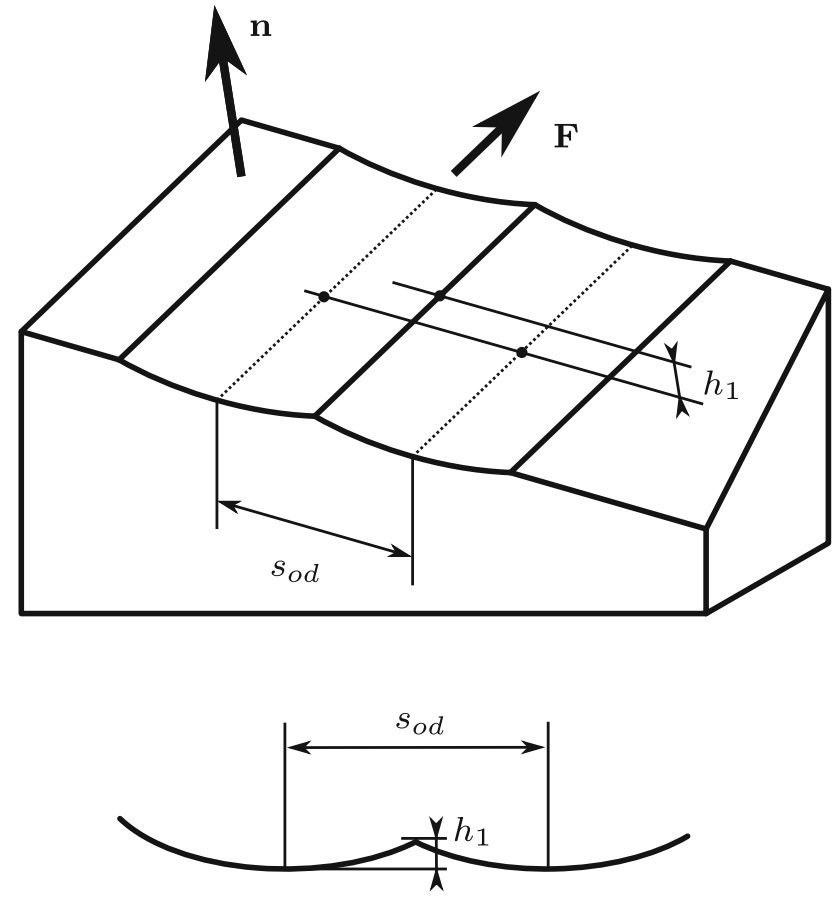

Machining direction $\mathbf{F}$

Fig. 5 Illustrating the scallop height and step over distance parameters

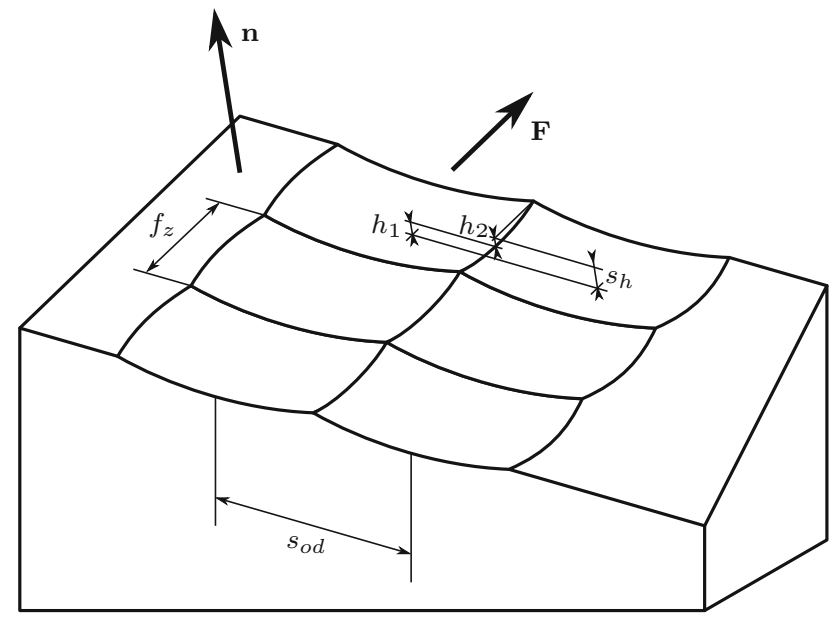

Fig. 6 Illustration in particular case of fitting between successive secondary scallop peaks

To take into account the effect of the feedrate on the scallop height, configuration of calculation is shown on Fig. 6, and the total scallop height $s_{h}$ is determined by adding up the scallop height $h_{1}$ due to the step over distance to the secondary scallop height $h_{2}$ due to feed rate. The same manner as $h_{1}, h_{2}$ secondary scallop height is determined according to the normal to the nominal profile. The same approximation done in $h_{1}$ calculation leads to: 
$h_{2}=T R_{e f f}-\sqrt{T R_{e f f}^{2}-\frac{f_{z}^{2}}{4}}$

then

$s_{h}=h_{1}+h_{2}$

Using the presented formulas (Eqs. 13-15), it is now possible to evaluate the scallop height by adding $h_{1}$, that can be piloted by the step over distance, and $h_{2}$, that can be piloted by adjusting the feed rate.

\section{Taking runouts into consideration}

Let us denote $a r_{o}$ the axial runout value and $r r_{o}$ the radial runout value (see Fig. 7), assuming that these values are small compared to those of feed per tooth. Since $h_{1}$ and $h_{2}$ are defined in planes respectively orthogonal and along to feed direction, the effects of the runout are very different upon $h_{1}$ and $h_{2}$.

Considering the cutter motion, the scallop height $h_{1}$ may be affected by $r r_{o}$ only. Indeed, the axial runout will solely offset the resulting machined surface by $a r_{o}$. Otherwise, the radial runout effect on $h_{1}$ may be quantified by considering a cutter radius of $\left(R+r r_{o}\right)$ instead of $R$ in formula 3 .

Concerning the scallop height $h_{2}$, the effect of the runout is more complex to analyse since in this case, the runout affects directly the feed per tooth value $f_{z}$. The studied configuration is presented in Fig. 7. In this configuration, the slope $\theta$ of the surface along the machining direction is defined as follows:

$\theta=S \cos (\alpha)$

and the effective feedrate/tooth due to runout is given by:

$f_{z}^{\prime}=\sqrt{\left(f_{z} \cos (\theta)+r r_{o}\right)^{2}+\left(f_{z} \sin (\theta)-a r_{0}\right)^{2}}$

Actually, this configuration corresponds to the machining case where the cutter contact point is situated on to the front of the cutter, which only happens during machining along the steepest slope. When the cutter contact point is not located on to the front of the cutter the radial runout should be projected on to the feed plane (n, F) because the scallop height is measured in this plane. Thus, the effective influence of the radial runout is always lesser than the nominal radial runout influence.

Then, taking runout into consideration, an upper bound for the machined scallop height along the feed direction becomes:

$h_{2}^{\prime}=T R_{e f f}-\sqrt{T R_{e f f}^{2}-\frac{f_{z}^{\prime 2}}{4}}$

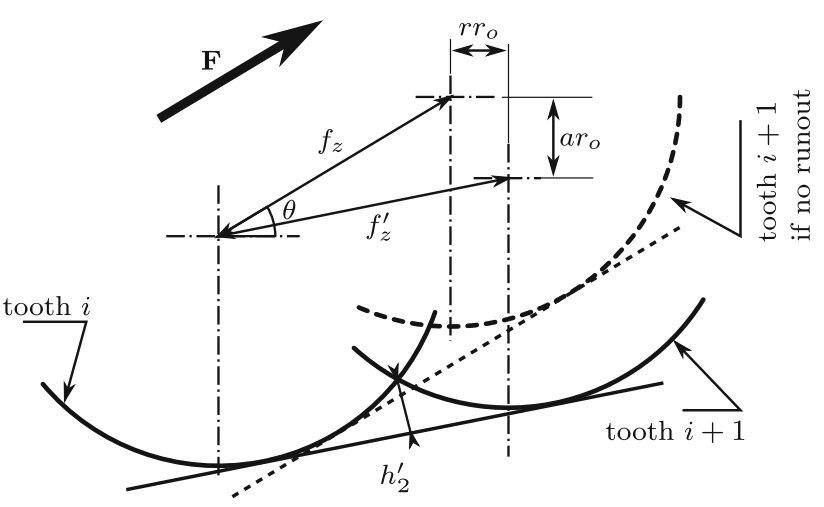

Fig. 7 Effect of runout on secondary scallop height

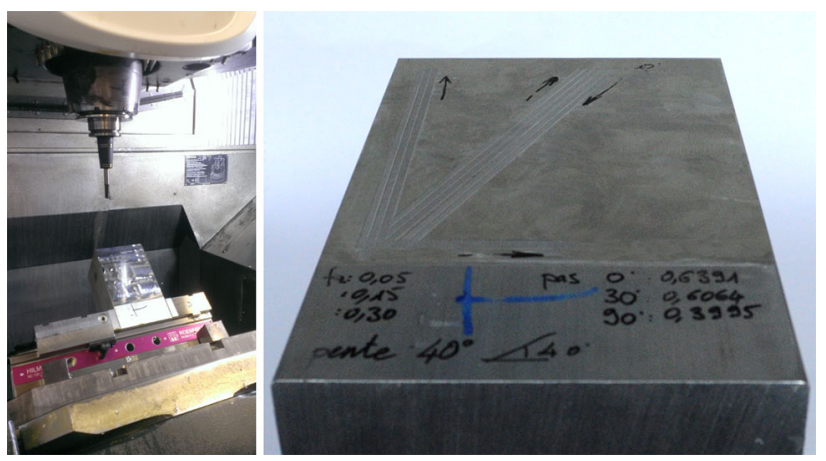

Fig. 8 Experimental study part

Moreover, the runout effects are highly dependant on the machining configuration. Indeed, in the case of a surface locally horizontal $(S=0)$, the axial runout have a predominant influence on the scallop height between the passage of two successive teeth, so $r_{o}=a r_{o}$. For machining a surface locally vertical $\left(S=\frac{\pi}{2}\right)$, the radial runout will have a predominant influence on the peak height between the passage of two successive teeth.

The previous equations are valid in configurations where the runout is small enough so that all the teeth can leave a trace on the workpiece during machining. Otherwise, a cutter having a number of teeth less than the actual number should be taken into consideration to perform the calculation.

The use of the above formulas makes it possible to estimate the total scallop height taking into account the combined effects of the feed rate and of the possible defects in the positioning of cutting tips.

\section{Model validation}

An additional experimental study was conducted to validate the theoretical model detailed before. The test part is made from a 2024 aluminum alloy block. The upper surface of the 
Table 1 Feed rates used for tests

\begin{tabular}{llll}
\hline Feed per tooth $(\mathrm{mm} / \mathrm{tooth})$ & 0.05 & 0.15 & 0.30 \\
Feed rate $(\mathrm{mm} / \mathrm{min})$ & 2000 & 6000 & 12,000 \\
\hline
\end{tabular}

Table 2 Parameters used for tests

\begin{tabular}{lll}
\hline $\begin{array}{l}\text { Machining } \\
\text { direction } \alpha\end{array}$ & $\begin{array}{l}\text { Feed per tooth } \\
f_{z}(\mathrm{~mm} / \text { tooth })\end{array}$ & $\begin{array}{l}\text { Step over distance } \\
s_{\text {od }}(\mathrm{mm})\end{array}$ \\
\hline $0^{\circ}$ & $0.005 ; 0.15 ; 0.3$ & 0.73 \\
$30^{\circ}$ & $0.005 ; 0.15 ; 0.3$ & 0.687 \\
$90^{\circ}$ & $0.005 ; 0.15 ; 0.3$ & 0.4 \\
\hline
\end{tabular}

block is planned before tilting the part by an angle $S=40^{\circ}$ (Fig. 8).

To conduct this experimental study, a plane has been chosen to be machined. This choice makes it possible to keep constant the value of the influential parameters $(\alpha, S$ and $\theta)$ all over the whole trajectory.

In this configuration, the cutter paths are made along values of $0^{\circ}, 30^{\circ}$ and $90^{\circ}$ of the angle $\alpha$, called the machining direction. For each direction, 3 paths are performed for each of the feed rate $f_{z}=0.05,0.15$ and $0.3 \mathrm{~mm} /$ tooth $(9$ paths for each direction). The machine used is a DMU85 monoBLOCK equipped with a Siemens 840D CNC controller. The tool is a solid carbide torus milling cutter with 4 teeth Sandvik R216.24-10050EAK22P 1620 with radii $R=5 \mathrm{~mm}$ and $r=2 \mathrm{~mm}$. Considering the aluminum alloy and the cutter used the cutting speed is set to $314 \mathrm{~m} / \mathrm{min}$ which is within the range of commonly used values in this case. Then the spindle rotation is constant and set to 10,000 $\mathrm{rpm}$. Feed rates corresponding to feed per tooth values chosen are stated in Table 1.

Note that the cutting conditions used in the different test cases do all of them comply with tool manufacturer recommendations.

The step over distances used for these tests are summarized in Table 2. They are determined such that the height $h_{1}$ of scallop height, due to the only step over distance, is equal to $0.01 \mathrm{~mm}$, following the methodology described in Senatore et al. (2012). The $0.01 \mathrm{~mm}$ value corresponds to a current value adopted for the finishing of molds and dies before final polishing operation.

The runouts are measured using gauge measurement station Zoller Genius 3. The tooth protruding less is taken as reference and is denoted "tooth 1", and then they are numbered in the order of their entry into the material (1-4). The values of the runouts are measured along the normal to the contact point and quantified with reference to the tooth 1 (see Table 3).

Surface measurements are done with an optical 3D measurement system Alicona Infinite SL. The analysis software
Table 3 Runout for each teeth

\begin{tabular}{ll}
\hline Teeth index & Runout at contact point $(\mu \mathrm{m})$ \\
\hline 1 & $\mathrm{R} 1=0.0$ \\
2 & $\mathrm{R} 2=0.1$ \\
3 & $\mathrm{R} 3=0.1$ \\
4 & $\mathrm{R} 4=0.2$ \\
\hline
\end{tabular}

is used to extract different quantities from the measurement of the initial surface. An example of this analysis results is presented on Fig. 9. The upper part of this figure shows the topology of the surface obtained measured transversely to the feedrate direction, and the lower part of the same figure presents a measurement along feedrate direction. On both screenshots, the bold yellow line clearly shows the measured profile. Moreover, the significant height values have been zoomed to improve readability, and the scallop height calculation method (which take into account the surface inclination) has been highlighted in red. ${ }^{1}$

Measurements are compared to the predictive model results presented in the previous sections. It is remind that the expected theoretical scallop height $h_{1}$, calculated from current methods detailed in Senatore et al. (2012) and Redonnet et al. (2013), is constant and equal to $0.01 \mathrm{~mm}$ (i.e. $10 \mu \mathrm{m}$ ). It is this criterion that was used to calculate the theoretical step over distance that would give a $0.01 \mathrm{~mm}$ scallop height without considering the effect of the feed rate. These values were chosen according to the existing strategies to date that do not allow quantifying the effect of feed rate on the peak height.

Tables 4, 5 and 6 show the results obtained for different orientations of the feed direction. In these tables $h_{1}$ and $h_{2}$ refer to the quantities presented in "Analysis of the expression of transverse effective radius" section and illustrated on Fig. 6.

These tables show that the experimental results for the $h_{1}$ scallop height are very close to the theoretical calculated ones. Indeed measured values are always between 9.5 and 9.7 $\mu \mathrm{m}$ while the expected value is $10 \mu \mathrm{m}$. These figures correspond to a differences included in a 3-5\% interval. On the $h_{2}$ scallop height side, the experimental results are also very close to the theoretical calculated ones. Figure 10 shows both experimental values of $h_{2}$ and theoretical values computed using Eqs. (14) and (8).

These results validate the theoretical model we are proposing to calculate the secondary scallop height $h_{2}$.

\footnotetext{
1 Actually the final value of the scallop height is directly provided by the analysis software of the measurement device that compute an average value along the whole measured profile.
} 


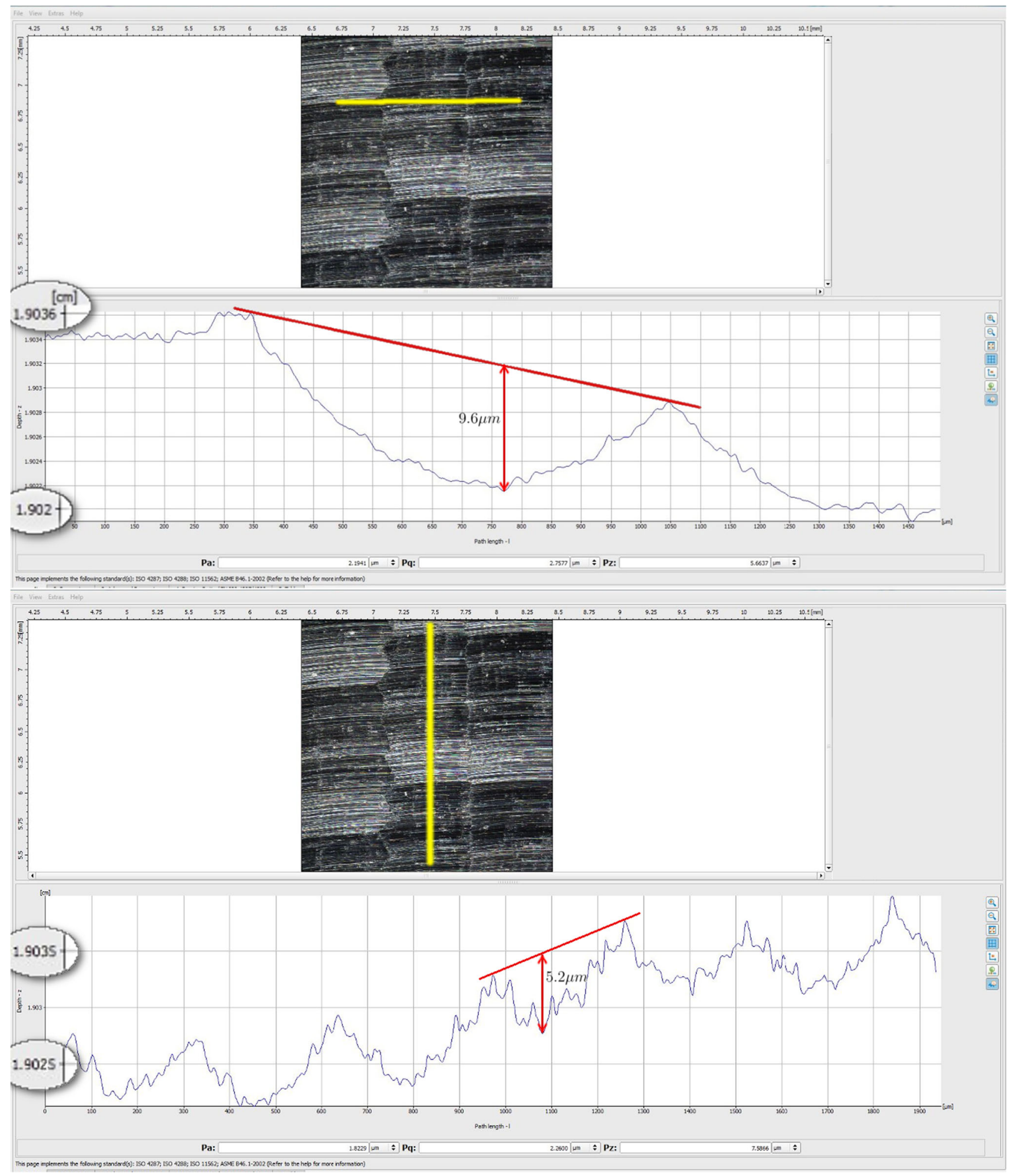

Fig. 9 Topological analysis for $\alpha=0^{\circ}, f=0.3 \mathrm{~mm} /$ tooth. Highlights the $h_{1}$ scallop height (top) and the $h_{2}$ scallop height (bottom) 
Table 4 Results for $\alpha=0^{\circ}$

\begin{tabular}{|c|c|c|c|c|c|c|}
\hline \multicolumn{7}{|c|}{$\alpha=0^{\circ}, s_{o d}=0.73 \mathrm{~mm}$} \\
\hline \multirow[t]{2}{*}{$f_{z}(\mathrm{~mm} / \mathrm{t})}$. & \multicolumn{2}{|l|}{$h_{1}$} & \multicolumn{2}{|l|}{$\underline{h_{2}}$} & \multicolumn{2}{|c|}{$\underline{s_{h}=h_{1}+h_{2}}$} \\
\hline & $\exp (\mu \mathrm{m})$ & th $(\mu \mathrm{m})$ & $\exp (\mu \mathrm{m})$ & th $(\mu \mathrm{m})$ & $\exp (\mu \mathrm{m})$ & th $(\mu \mathrm{m})$ \\
\hline 0.05 & 9.5 & 10 & 0.2 & 0.1 & 9.7 & 10.1 \\
\hline 0.15 & 9.6 & 10 & 1.4 & 1.4 & 11 & 11.4 \\
\hline 0.30 & 9.6 & 10 & 5.2 & 5.6 & 14.8 & 15.6 \\
\hline
\end{tabular}

Table 5 Results for $\alpha=30^{\circ}$

\begin{tabular}{|c|c|c|c|c|c|c|}
\hline \multicolumn{7}{|c|}{$\alpha=30^{\circ}, s_{o d}=0.687 \mathrm{~mm}$} \\
\hline \multirow[t]{2}{*}{$f_{z}(\mathrm{~mm} / \mathrm{t})}$. & \multicolumn{2}{|l|}{$h_{1}$} & \multicolumn{2}{|l|}{$h_{2}$} & \multicolumn{2}{|c|}{$s_{h}=h_{1}+h_{2}$} \\
\hline & $\exp (\mu \mathrm{m})$ & th $(\mu \mathrm{m})$ & $\exp (\mu \mathrm{m})$ & th $(\mu \mathrm{m})$ & $\exp (\mu \mathrm{m})$ & th $(\mu \mathrm{m})$ \\
\hline 0.05 & 9.7 & 10 & 0.2 & 0.1 & 9.9 & 10.1 \\
\hline 0.15 & 9.6 & 10 & 0.8 & 0.8 & 10.4 & 10.8 \\
\hline 0.30 & 9.6 & 10 & 3.2 & 3 & 12.8 & 13 \\
\hline
\end{tabular}

Table 6 Results for $\alpha=90^{\circ}$

\begin{tabular}{|c|c|c|c|c|c|c|}
\hline \multicolumn{7}{|c|}{$\alpha=90^{\circ}, s_{o d}=0.4 \mathrm{~mm}$} \\
\hline \multirow[t]{2}{*}{$\bar{f}(\mathrm{~mm} / \mathrm{t})}$. & \multicolumn{2}{|l|}{$h_{1}$} & \multicolumn{2}{|l|}{$\underline{h_{2}}$} & \multicolumn{2}{|c|}{$\underline{s_{h}}=h_{1}+h_{2}$} \\
\hline & $\exp (\mu \mathrm{m})$ & th $(\mu \mathrm{m})$ & $\exp (\mu \mathrm{m})$ & th $(\mu \mathrm{m})$ & $\exp (\mu \mathrm{m})$ & th $(\mu \mathrm{m})$ \\
\hline 0.05 & 9.7 & 10 & 0.2 & 0.1 & 9.9 & 10.1 \\
\hline 0.15 & 9.6 & 10 & 0.5 & 0.4 & 10.1 & 10.4 \\
\hline 0.30 & 9.7 & 10 & 1.9 & 1.7 & 11.6 & 11.7 \\
\hline
\end{tabular}

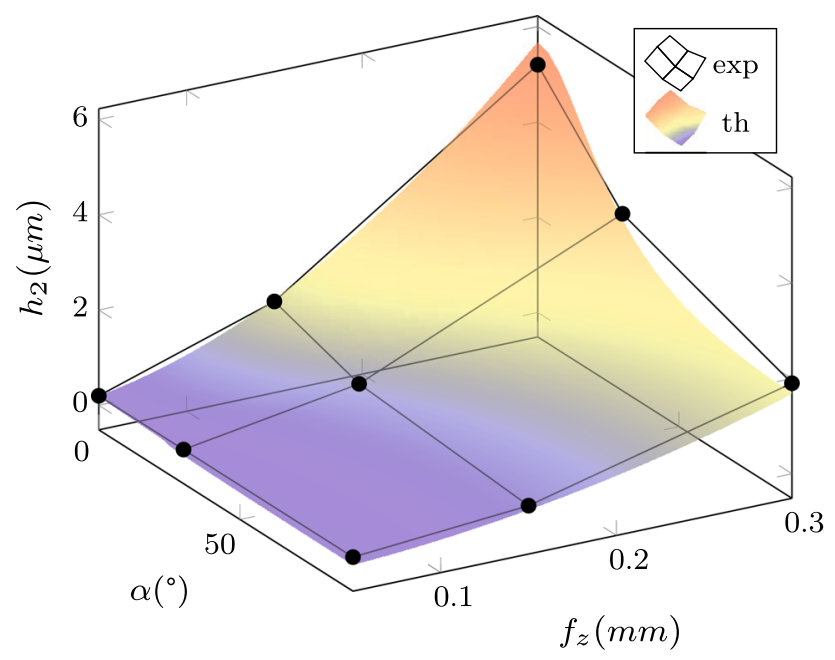

Fig. 10 Comparison between $h_{2}$ theoretical calculation and experimental results

\section{Analysis and discussion}

\section{Analysis and exploitation of the results}

The respective shares of $h_{1}$ and $h_{2}$ in the total scallop height $s_{h}$ are shown in Figs. 11 (absolute) and 12 (in percentage). These figures show how $h_{2}$ may be quite significant in some cases.

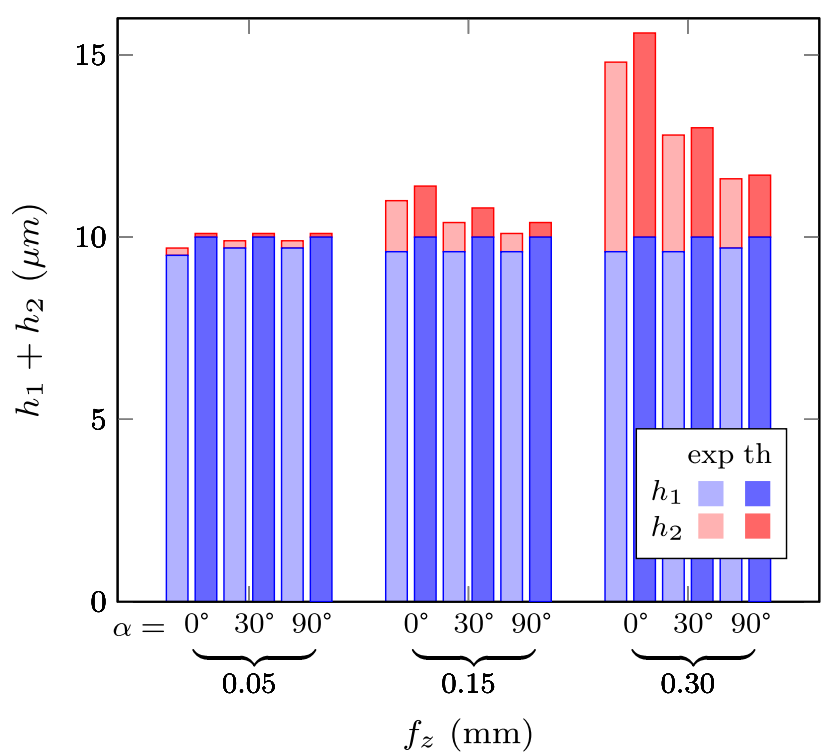

Fig. 11 Theoretical and experimental results (numeric values)

For each of the cases studied, Table 7 compares the error committed between the theoretical model and the experimental results, taking account of $h_{1}$ and $h_{2}$ on the one hand and only taking account of $h_{1}$ on the other hand.

This table shows that taking account of $h_{1}$ and $h_{2}$, the error committed on the calculation of the scallop height is 


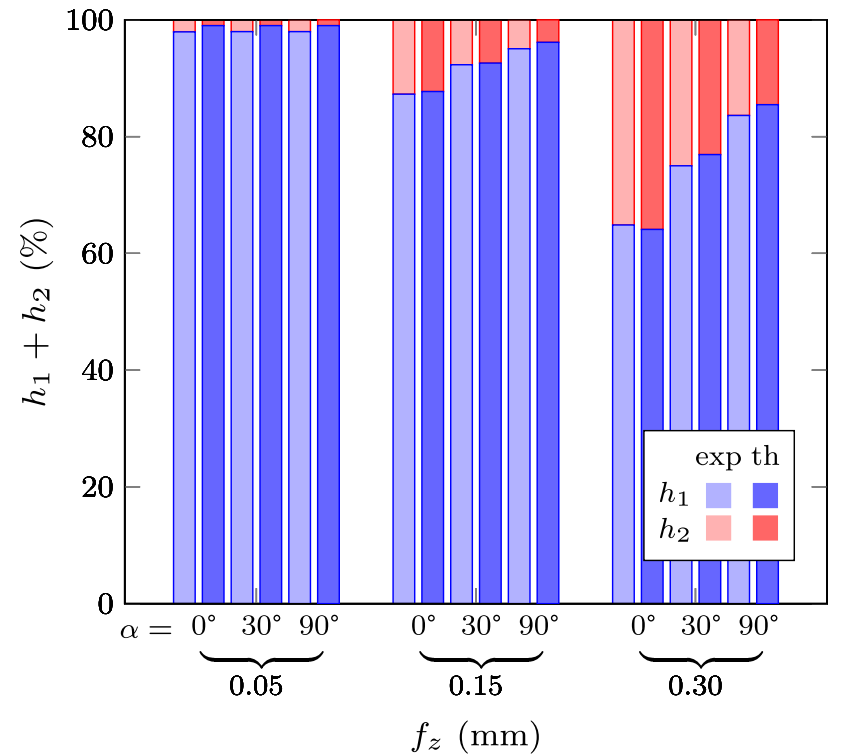

Fig. 12 Theoretical and experimental results (shares)

always less than $6 \%$, whereas by considering only $h_{1}$ the error committed may exceed $38 \%$.

The presented results also allow to calculate the percentage of total scallop height $\left(s_{h}\right)$ underestimation when taking into account only $h_{1}$ value. For example, in the worst case (i.e. $\alpha=0^{\circ}$ ), if the user choose a $5 \%$ threshold value of the scallop height underestimation, then the machining feedrate should not exceed $0.08 \mathrm{~mm}$.

The values of tool runout remain small compared to process variables, particularly for the feed rates of 0.15 and $0.3 \mathrm{~mm} /$ tooth. The analysis of Fig. 9 shows that the teeth marks left in the adjacent grooves are not necessarily fitting. The lowest points are thus not necessarily in vis-a-vis in the neighboring scallop, it is necessary to locate the teeth traces of passages for positioning the measuring line and determine the heights $h_{1}$ and $h_{2}$.

These results may be exploited directly by including the evaluation of $h_{2}$ into tool path planning algorithms. Most of the time, this should be easy to do because of the simplicity of the analytical model proposed. However, users must be aware of the limitations of the model that are discussed in the next section.

\section{Discussion}

In this paper, a model taking into account the feed rate for calculation of the scallop height of end-milled free-form surfaces is proposed. The limits of this model are discussed here after:

- tool motion must be a pure translation. This implies the whole results are fully valid for 3-axis machining strategies. It also can be used for 5-axis machining strategies when rotation axes are not used between two points $(3+2$ axes). However full 5-axis machining strategies are still out of the application field of the present work.

- the model is not valid when the local slope of the surface is zero ( $S=0$ in Eq. 8). Actually in this case the calculated effective radius approaches infinity. This case corresponds to the special machining configuration: endmilling of an horizontal plane. Indeed this machining configuration is well-known and does not require any further study.

Apart considering these limits some other considerations may be discussed:

Firstly, the scallop height calculation relies on the assumption that the surface is locally considered planar. "Appendix" shows that the scallop height calculated without taking into account the local curvature is equivalent to the scallop height calculated taking the local curvature into account, when the local radius of curvature tends towards infinity. Thus the assumption made to calculate the scallop height is valid as long as the local radius of curvature of the surface is much larger than the other dimensions. Furthermore experimental
Table 7 Percentage error of both models compared to experimental results

\begin{tabular}{llll}
\hline$\alpha$ & $f_{z}(\mathrm{~mm} /$ tooth $)$ & Error & \\
\cline { 3 - 4 } & & Model based on $h_{1}$ only $(\%)$ & Model based on $h_{1}+h_{2}(\%)$ \\
\hline $0^{\circ}$ & 0.05 & 5.9 & 4 \\
& 0.15 & 15.8 & 3.5 \\
& 0.30 & 38.5 & 5.1 \\
$30^{\circ}$ & 0.05 & 4 & 2 \\
& 0.15 & 11.1 & 3.7 \\
& 0.30 & 26.2 & 1.5 \\
$90^{\circ}$ & 0.05 & 4 & 2 \\
& 0.15 & 7.7 & 2.9 \\
& 0.30 & 17.1 & 0.8 \\
\hline
\end{tabular}


results show that the calculated values of scallop heights are very close to the measured ones.

Application of this work to full 5-axis machining needs a large number of modifications because many assumptions have to be reconsidered. Furthermore, when using 5-axis machining, the effective feedrate is often far less from programmed one. Thus it can be supposed that the $h_{2}$ influence on the final surface roughness if less important.

Reader can note that the obtained results do not depend on teeth number nor spindle speed. Actually the presented model is based on feed per tooth and cutting speed only. However cutting conditions have to comply with tool manufacturer recommendations to insure a smooth running of the cutting process. This point guarantees that the surface left by the tool is not affected by pull-outs phenomenon that is not taken into account by the presented model.

Moreover, the proposed model relies exclusively on analytical calculations. Thus its implementation allows very fast computation. Therefore the fast and accurate computation of local surface roughness may be considered as a major interest for the present paper.

The effect of feedrate on total scallop height is the most important when machining at high feedrate along the steepest slope direction. As it can be observed in Table 4 and Fig. 12, the scallop height $h_{2}$ can reach up to $30 \%$ of the total scallop height. Indeed, this point is important since, when using torical mill, the optimal machining direction is precisely the steepest slope direction. As stated in Lasemi et al. (2010) and Redonnet et al. (2016) the maximal removal rate is actually reached when machining along this direction.

\section{Conclusion}

This study demonstrates that the influence of the feed rate of a torus milling cutter on the surface roughness cannot always be neglected. Actually, the secondary scallop height induced by successive passes of the cutting teeth can easily reach $30 \%$ of the total scallop height. Furthermore this configuration occurs when machining along the direction of steepest slope $\left(\alpha=0^{\circ}\right)$, which is the optimal machining direction (in terms of material removal rate) when using a torus-end mill.

It can be noticed that these results have been obtained using feed rates compatible with the requirements of the tool manufacturer.

This study presents an analytical model that can easily and quickly be used to calculate the total scallop height, taking into account the effect of the feed rate. This model is validated in different machining configuration allowing highlighting that the prediction provided by the analytical model does not deviate by more than $5 \%$ of the measured value.

The use of the analytical model, by its simplicity, may allow to further improving the tool path by adjusting the mill feed rate depending on its location on the workpiece. This will satisfy two important criteria. On the one hand this will further decrease machining time while respecting maximum scallop height criteria. On the other hand it will homogenize the workpiece surface roughness by ensuring that at any point of the surface of the total scallop peak height is equal to the maximum allowable value. This provides the significant advantage of facilitating the finish polishing operation since the amount of material to be removed will be more homogeneous.

As a short term perspective the authors plan to apply this new method for calculation of the effective scallop height to recent toolpath planning algorithms such as zone machining algorithms described in Perles et al. (2015) and Djebali et al. (2015). Indeed, in the context of toolpath planning process the present work may be very useful to define the most efficient feedrate.

As a longer term perspective, the authors may consider the extension of the present work to 5-axis machining of free form surface.

\section{Appendix: Scallop height approximation}

Considering $\varrho$ the curvature of the surface locally constant, the scallop height calculation is based on the equation:

$R_{\text {eff }}^{2}=\left(\varrho+h_{1}\right)^{2}+\left(\varrho+R_{e f f}\right)^{2}-2 \cos (\beta)\left(\varrho+R_{e f f}\right)\left(\varrho+h_{1}\right)$

From this equation the following can be calculated:

$\cos (\beta)=\frac{2 \varrho^{2}+2 \varrho R_{e f f}+2 \varrho h_{1}+h_{1}^{2}}{2\left(\varrho+R_{e f f}\right)\left(\varrho+h_{1}\right)}$

$h_{1}^{2}$ may be considered negligible in comparison with other quantities. Thus:

$\cos (\beta)=\frac{2 \varrho^{2}+2 \varrho R_{e f f}+2 \varrho h_{1}}{2\left(\varrho+R_{e f f}\right)\left(\varrho+h_{1}\right)}$

Considering $s_{\text {od }}$ the distance between the two contact points (see Figs. 4, 5), the following can be stated:

$\sin (\beta)=\frac{s_{\text {od }}}{2 \varrho}$

Using the fact that $\sin ^{2}(\beta)=1-\cos ^{2}(\beta)$ it can be deduced that:

$\left(\frac{s_{o d}}{2 \varrho}\right)^{2}=1-\left(\frac{2 \varrho^{2}+2 \varrho R_{e f f}+2 \varrho h_{1}}{2\left(\varrho+R_{e f f}\right)\left(\varrho+h_{1}\right)}\right)^{2}$ 
whence

$$
\begin{aligned}
\frac{s_{o d}^{2}}{4 \varrho^{2}} & =1-\frac{\left(\varrho^{2}+\varrho R_{e f f}+\varrho h_{1}\right)^{2}}{\left(\left(\varrho+R_{e f f}\right)\left(\varrho+h_{1}\right)\right)^{2}} \\
& =\frac{\left(\left(\varrho+R_{e f f}\right)\left(\varrho+h_{1}\right)\right)^{2}-\left(\varrho^{2}+\varrho R_{e f f}+\varrho h_{1}\right)^{2}}{\left(\left(\varrho+R_{e f f}\right)\left(\varrho+h_{1}\right)\right)^{2}} \\
& =\frac{R_{e f f} h_{1}\left(2 \varrho^{2}+2 \varrho R_{e f f}+2 \varrho h_{1}+R_{e f f} h_{1}\right)}{\left(\varrho+R_{e f f}\right)^{2}\left(\varrho+h_{1}\right)^{2}} \\
& =\frac{R_{e f f} h_{1}\left(2 \varrho\left(\varrho+R_{e f f}+h_{1}\right)+R_{e f f} h_{1}\right)}{\left(\varrho+R_{e f f}\right)^{2}\left(\varrho+h_{1}\right)^{2}}
\end{aligned}
$$

$h_{1}$ may be considered negligible when added with $\varrho$. Thus:

$$
\begin{aligned}
\frac{s_{o d}^{2}}{4 \varrho^{2}} & =\frac{R_{e f f} h_{1}\left(2 \varrho^{2}+2 \varrho R_{e f f}+R_{e f f} h_{1}\right)}{\varrho^{2}\left(\varrho+R_{e f f}\right)^{2}} \\
& =\frac{R_{e f f} h_{1}\left(2 \varrho^{2}+R_{e f f}\left(2 \varrho+h_{1}\right)\right)}{\varrho^{2}\left(\varrho+R_{e f f}\right)^{2}}
\end{aligned}
$$

again $h_{1}$ may be considered negligible when added with $\varrho$. Thus:

$$
\begin{aligned}
\frac{s_{o d}^{2}}{4 \varrho^{2}} & =\frac{R_{e f f} h_{1}\left(2 \varrho^{2}+2 \varrho R_{e f f}\right)}{\varrho^{2}\left(\varrho+R_{e f f}\right)^{2}} \\
& =\frac{2 \varrho R_{e f f} h_{1}\left(\varrho+R_{e f f}\right)}{\varrho^{2}\left(\varrho+R_{e f f}\right)^{2}} \\
& =\frac{2 R_{e f f} h_{1}}{\varrho\left(\varrho+R_{e f f}\right)}
\end{aligned}
$$

Finally the expression of $h_{1}$ is:

$$
h_{1}=\frac{s_{o d}^{2}\left(\varrho+R_{e f f}\right)}{8 \varrho R_{e f f}}
$$

Calculation of the scallop height $h_{1 p}$ for a plane surface is directly derived of the equation:

$$
R_{e f f}^{2}=\left(\frac{s_{o d}}{2}\right)^{2}+\left(R_{e f f}-h_{1 p}\right)^{2}
$$

which, considering $h_{1 p}^{2}$ negligible in comparison with other quantities, leads to:

$$
h_{1 p}=\frac{s_{o d}^{2}}{8 R_{e f f}}
$$

Thus, considering that

$$
\lim _{\varrho \rightarrow \infty} \frac{s_{o d}^{2}\left(\varrho+R_{e f f}\right)}{8 \varrho R_{e f f}}=\frac{s_{o d}^{2}}{8 R_{e f f}}
$$

the following can be stated:

$\lim _{\varrho \rightarrow \infty} h_{1}=h_{1 p}$

\section{References}

Bedi, D. S., Ismail, F., Mahjoob, M. J., \& Chen, Y. (1997). Toroidal versus ball nose and flat bottom end mills. The International Journal of Advanced Manufacturing Technology, 13(5), 326-332. doi:10. 1007/BF01178252.

Can, A., \& Ünüvar, A. (2010). A novel iso-scallop tool-path generation for efficient five-axis machining of free-form surfaces. The International Journal of Advanced Manufacturing Technology, 51(9-12), 1083-1098. doi:10.1007/s00170-010-2698-z.

Chețan, P., Boloş, V., Pozdîrcă, A., \& Peterlicean, A. (2014). Influence of radial finishing trajectories to the roughness obtained by milling of spherical surfaces. Procedia Technology, 12, 420-426. doi:10. 1016/j.protcy.2013.12.508.

Cheţn, P., Boloş, V., \& Pozdîrcă, A. (2014). Influence of plane-parallel finishing trajectories to the roughness obtained by milling of spherical surfaces. Procedia Technology, 12, 411-419. doi:10.1016/j. protcy.2013.12.507.

Chen, Z. C., \& Song, D. (2006). A practical approach to generating accurate iso-cusped tool paths for three-axis CNC milling of sculptured surface parts. Journal of Manufacturing Processes, 8(1), 29-38. doi:10.1016/S1526-6125(06)70099-8.

Cho, H., Jun, Y., \& Yang, M. (1993). 5-axis CNC milling for effective machining of sculptured surfaces. International Journal of Production Research, 31(11), 2559-2573.

Denkena, B., de Leon, L., Turger, A., \& Behrens, L. (2010). Prediction of contact conditions and theoretical roughness in manufacturing of complex implants by toric grinding tools. International Journal of Machine Tools and Manufacture, 50(7), 630-636. doi:10.1016/ j.ijmachtools.2010.03.008.

Denkena, B., Köhler, J., \& van der Meer, M. (2013). A roughness model for the machining of biomedical ceramics by toric grinding pins. CIRP Journal of Manufacturing Science and Technology, 6(1), 22-33. doi:10.1016/j.cirpj.2012.07.002.

Djebali, S., Segonds, S., Redonnet, J. M., \& Rubio, W. (2015). Using the global optimisation methods to minimise the machining path length of the free-form surfaces in three-axis milling. International Journal of Production Research, 53(17), 5296-5309.

Du, J., Xg, Y., \& Xt, T. (2012). The avoidance of cutter gouging in fiveaxis machining with a fillet-end milling cutter. The International Journal of Advanced Manufacturing Technology, 62(1-4), 89-97.

Duan, X., Peng, F., Yan, R., Zhu, Z., \& Li, B. (2015). Experimental study of the effect of tool orientation on cutter deflection in five-axis filleted end dry milling of ultrahigh-strength steel. The International Journal of Advanced Manufacturing Technology, 81(1-4), 653666.

He, Y., \& Chen, Z. T. (2016). Achieving quasi constant machining strip width in five-axis frontal grinding with toroidal tools. Proceedings of the Institution of Mechanical Engineers, Part B: Journal of Engineering Manufacture, 230(3), 587-592.

Kim, B., \& Chu, C. (1994). Effect of cutter mark on surface roughness and scallop height in sculptured surface machining. ComputerAided Design, 26(3), 179-188.

Kim, B. H., \& Chu, C. N. (1999). Texture prediction of milled surfaces using texture superposition method. Computer-Aided Design, 31(8), 485-494. doi:10.1016/S0010-4485(99)00045-7.

Lasemi, A., Xue, D., \& Gu, P. (2010). Recent development in CNC machining of freeform surfaces: A state-of-the-art review. 
Computer-Aided Design, 42(7), 641-654. doi:10.1016/j.cad.2010. 04.002 .

Lee, Y. S. (1998). Non-isoparametric tool path planning by machining strip evaluation for 5 -axis sculptured surface machining. Computer-Aided Design, 30(7), 559-570. doi:10.1016/ S0010-4485(98)00822-7.

Lin, R. S., \& Koren, Y. (1996). Efficient tool-path planning for machining free-form surfaces. Journal of Engineering for Industry, 118(1), 20-28. doi:10.1115/1.2803642.

Perles, A., Djebali, S., Lemouzy, S., Segonds, S., Redonnet, J. M., \& Rubio, W. (2015). Milling plan optimization with an emergent problemsolving approach. Computers \& Industrial Engineering, 87, 506-517. doi:10.1016/j.cie.2015.05.025.

Pi, J., Red, E., \& Jensen, G. (1998). Grind-free tool path generation for five-axis surface machining. Computer Integrated Manufacturing Systems, 11(4), 337-350. doi:10.1016/S0951-5240(98)00033-0.

Redonnet, J. M., Rubio, W., Monies, F., \& Dessein, G. (2000). Optimising tool positioning for end-mill machining of free-form surfaces on 5-axis machines for both semi-finishing and finishing. The International Journal of Advanced Manufacturing Technology, 16(6), 383-391.
Redonnet, J. M., Djebali, S., Segonds, S., Senatore, J., \& Rubio, W. (2013). Study of the effective cutter radius for end milling of freeform surfaces using a torus milling cutter. Computer-Aided Design, 45(6), 951-962. doi:10.1016/j.cad.2013.03.002.

Redonnet, J. M., Gamboa Vázquez, A., Traslosheros Michel, A., \& Segonds, S. (2016). Optimisation of free-form surface machining using parallel planes strategy and torus milling cutter. Proceedings of the Institution of Mechanical Engineers, Part B: Journal of Engineering Manufacture (in press)

Senatore, J., Segonds, S., Rubio, W., \& Dessein, G. (2012). Correlation between machining direction, cutter geometry and step-over distance in 3-axis milling: Application to milling by zones. Computer-Aided Design, 44(12), 1151-1160. doi:10.1016/j.cad. 2012.06.008.

Suresh, K., \& Yang, D. C. H. (1994). Constant scallop-height machining of free-form surfaces. Journal of Engineering for Industry, 116(2), 253-259. doi:10.1115/1.2901938.

Tai, C. C., \& Fuh, K. H. (1994). A predictive force model in ballend milling including eccentricity effects. International Journal of Machine Tools and Manufacture, 34(7), 959-979. doi:10.1016/ 0890-6955(94)90028-0. 